\title{
LA CONQUISTA DE TENOCHTITLAN:
}

\author{
MULTITUD DE VOCES, VISIONES Y ELABORACIONES \\ EN TORNO A LO REAL
}

\author{
THE CONQUEST OF \\ TENOCHTITLAN: \\ A MULTITUDE OF VOICES, \\ VISIONS AND ELABORATIONS AROUND REALITY
}

\author{
Clementina Battcock \\ Dirección de Estudios Históricos (INAH) \\ cbattcockdeh@gmail.com
}

Jhonnatan Alejandro Zavala López

Centro Educacional Tlaquepaque

jhonnatan.zavala@cetac.edu.mx

\begin{abstract}
The chronicles of the conquest wars of the 16th century are part of the writing practice that searched the social distinction and the formation of a corpus of records which legitimate the exercise of social dynamics in these unknown territories. This paper explores some of the elements that configure political power traces of New Spain, as well as the methods that have been used for its historiographic criticism.
\end{abstract}

Keywords: chronicle, relationship, conquest, record, memory.

\section{Resumen}

Las crónicas del siglo XVI de la guerra de conquista se insertan en la práctica de una escritura que buscaba la distinción social y la formación de un corpus de registros que legitiman el ejercicio de determinadas dinámicas sociales en estos desconocidos territorios. Este artículo explora algunos de los elementos que configuran los trazos de poder político del virreinato de la Nueva España, así como los métodos que son utilizados para su crítica historiográfica.

Palabras clave: crónica, relación, conquista, registro, memoria. 


\section{Introducción}

Este año se cumplirán 500 años de la conquista de Tenochtitlan a cargo de las tropas capitaneadas por Hernán Cortés. Este acontecimiento ha sido representado insistentemente como un determinante en el devenir histórico de numerosas sociedades actuales. Fueron los pensadores decimonónicos de las independencias de los estados poscoloniales quienes fabricaron el mito de lo mexicano a partir del espíritu de los vencidos. Así, la etapa novohispana fue opacada por el imperativo de construir una nación y forjar un panteón de héroes patrios; esta tarea derivó en una visión maniquea que concibe a la Conquista como un proceso en el que sólo habrían participado dos grupos, excluyendo a cualquier otro: los conquistadores europeos y los indígenas conquistados (figura 1).

Dicha visión invisibilizó la agencia de los múltiples actores que desarrollaron experiencias diferenciadas del proceso de conquista, en ocasiones bajo la formulación abierta de resistencias al proceso colonizador, forjadas al calor de la evangelización cristiana (Lienhard, 2008) y en tantas otras como operaciones de adaptación sistémica que buscaron articularse en torno al aparato virreinal de gobierno, elaborando estrategias no necesariamente vinculadas a verificar los hechos históricos, sino que buscaban como fin último el conservar, restituir o incrementar los privilegios que les eran otorgados de acuerdo con el cuerpo social del que formaban parte (Duve, 2007: 29-43).

Una de las estrategias de adaptación al proceso de conquista estuvo profundamente vinculada a un sistema de valores basados en la distinción social a través del honor y la memoria, en la que los sujetos letrados buscaban posicionarse como arquetipos de su tiempo construyendo obras narrativas que apelaban a la interlocución con lectores prestigiados en las órdenes clericales y en las cortes de las monarquías, para con ello fundarse un lugar social en la historia universal cristiana. Con base en este argu- mento, el presente artículo tiene por objetivo explorar la construcción de los registros y su formación social como memoria en la escritura de algunas de las crónicas de la conquista (Romero Galván, 2003: 11-20), así como las interpretaciones y análisis formulados por la investigación disciplinar que los estudios históricos han realizado durante las últimas décadas.

Concebimos a la memoria humana como un conjunto polisémico de procesos en los que intervienen ejercicios de conocimiento sistémicos del medio social, desde ejes políticos selectivos y con intencionalidades precisas, hasta los propios sentidos estimulados por las percepciones que produce la realidad.

Bajo esta premisa se sigue que toda acción de recordar o conmemorar no va de una reproducción objetiva de lo acontecido en lo real, sino que configura una reproducción de las acciones y el medio ambiente vivido de forma directa o indirecta (Feierstein, 2012: 24).

Desde hace ya unos años (Pastrana, 2004: 7-13; 211-270) el tema de la Conquista de México y de Mesoamérica está en pleno apogeo, pues voces disímiles han cuestionado y llamado a repensar esta materia desde otras perspectivas. Diversos investigadores nacionales e internacionales nos hemos dado a la tarea de revisar críticamente la forma en que el tópico ha sido analizado, interés que se ha manifestado en numerosos encuentros, foros, coloquios, mesas de discusión, proyectos de investigación y publicaciones.

La finalidad de la comunidad académica es proponer el uso de nuevas fuentes, enfoques y modelos teórico-metodológicos para abordar o replantear los numerosos problemas históricos en torno a la Conquista, así como cuestionar las verdades enunciadas como pretendidos absolutos en un pasado difícil de explicar y con ello penetrar en campos, hasta ahora ignorados, que nos permitan desentrañar los múltiples sentidos que la conciencia histórica le ha dado a distintas épocas.

En otras palabras, ¿por qué se recrean y trascienden a la posteridad estos aconteci- 
mientos? ¿Qué sentido se les otorga en la reelaboración de la historia oficial?

"La conquista indígena de Mesoamérica" es el nombre de uno de los enfoques que, desde hace más de una docena de años, ha proporcionado nuevas respuestas a la pregunta ¿quién conquistó México? Michel Oudijk (2007), Laura Matthew (2007), Matthew Restall (2007), Robinson Herrera (2007), Florine Asselberg (2007), entre otros, han evidenciado la gran relevancia de la participación de los indígenas, su origen, sus estructuras, dinámicas e instituciones, en la concreción de la Conquista. De esta forma, dichos investigadores han recurrido al análisis de documentos de archivo y documentos que consideran como crónicas de tradición mesoamericana que retratan a los indígenas como protagonistas de su historia y no como meros espectadores de procesos ajenos. Sin lugar a duda, estamos ya muy lejos de las miradas reduccionistas enmarcadas en el binomio dominadores-dominados o vencedores-vencidos que se construyó durante la última mitad del siglo $X X$, bajo el telón de un debate importante sobre la relevancia fundamental de la composición narrativa de las crónicas (León-Portilla, 1964).

Sin embargo, ese posicionamiento ante la escritura desdibujó la épica colonizadora fundada en un balance narrativo que buscaba encontrar en ella los orígenes convulsos de la nación (polémicamente entendida como sinónimo del complejo ideológico social estatal hegemónico) (Rozat, 2001), y que en consecuencia abrió posibilidades de contrastar las voces y las autorías que estructuraban la intencionalidad de los textos, incluso bajo la revisión de procesos concienciales que nutren la visión de los seres humanos sobre su época: nos referimos a la interpretación sobre el proceso cognitivo de los tiempos y los espacios narrados, percibidos y readaptados por sujetos dentro de un contexto específico (O'Gorman, 2007). ${ }^{1}$

\footnotetext{
1 "Las fuentes son de inspiración, no de autoridad; sirven para proporcionar imágenes, episodios y personajes del pasado que, sacados de su articulación histórica, hacen las veces de temas que se engarzan en una concatenación distinta a la concatenación espacio
}

Dicho lo anterior, podemos postular que los estudios históricos de las crónicas de la conquista castellana se enfilan hacia la búsqueda de un pasado maleable que se fundamenta en la experiencia histórica del sujeto que registra ese pasado por medio de la escritura.

Se registran voces, imágenes, lecturas e incluso paisajes a los cuales se les dota de sentido en un espacio sensible del cual el sujeto selecciona lo que le es trascendental en la forma de representar y representarse frente a otros con tal de reivindicar su diferencia, y con ello situarse como un nodo articulador de la memoria que toma su distancia del olvido y asume un rol estructurante en la lectura de su realidad, pues bajo su escritura se guarda un sitio para sí mismo y su legado en la memoria, pensado éste como un espacio trascendente a la existencia misma (Díez-Canedo, 2019: 103-132; Joutard, 1986: 239; Turner, 2016). ${ }^{2}$

\section{Sobre la Conquista y sus relatos}

\section{"Viajero: has llegado a la región más transparente del aire". Alfonso Reyes, Visión del Anáhuac (1519)}

El examen de los corpus documentales de la Conquista nos expresa que existen matices y medias tintas; que los partícipes de aquel proceso eran mucho más distintos, plurales y heterogéneos entre sí de lo que suponemos, incluso los que conformaban un mismo bando. Los conquistadores no eran aquella entidad homogénea y compacta de soldados en la que comúnmente solemos pensar, porque entre los castellanos y extremeños había también griegos, italianos e incluso combatientes y esclavos provenientes del África (Martínez Martínez, 2013). Por otra parte, entre los guerreros mexicas también había hombres de origen distinto, provenientes de ciudades aliadas o pueblos sometidos. Además, no todos los nahuas

temporal en que se dan" (O'Gorman, 2007: 63).

2 "Hay en este esfuerzo desesperado por retener lo que habitualmente deja pocas huellas, la angustia de la muerte, la angustia de la nada" (Joutard, 1986: 239). 


\section{Figura 1}

Anónimo. El encuentro de Cortés y Moctezuma. Col. Jay I. Kislak, Library of Congress, Washington

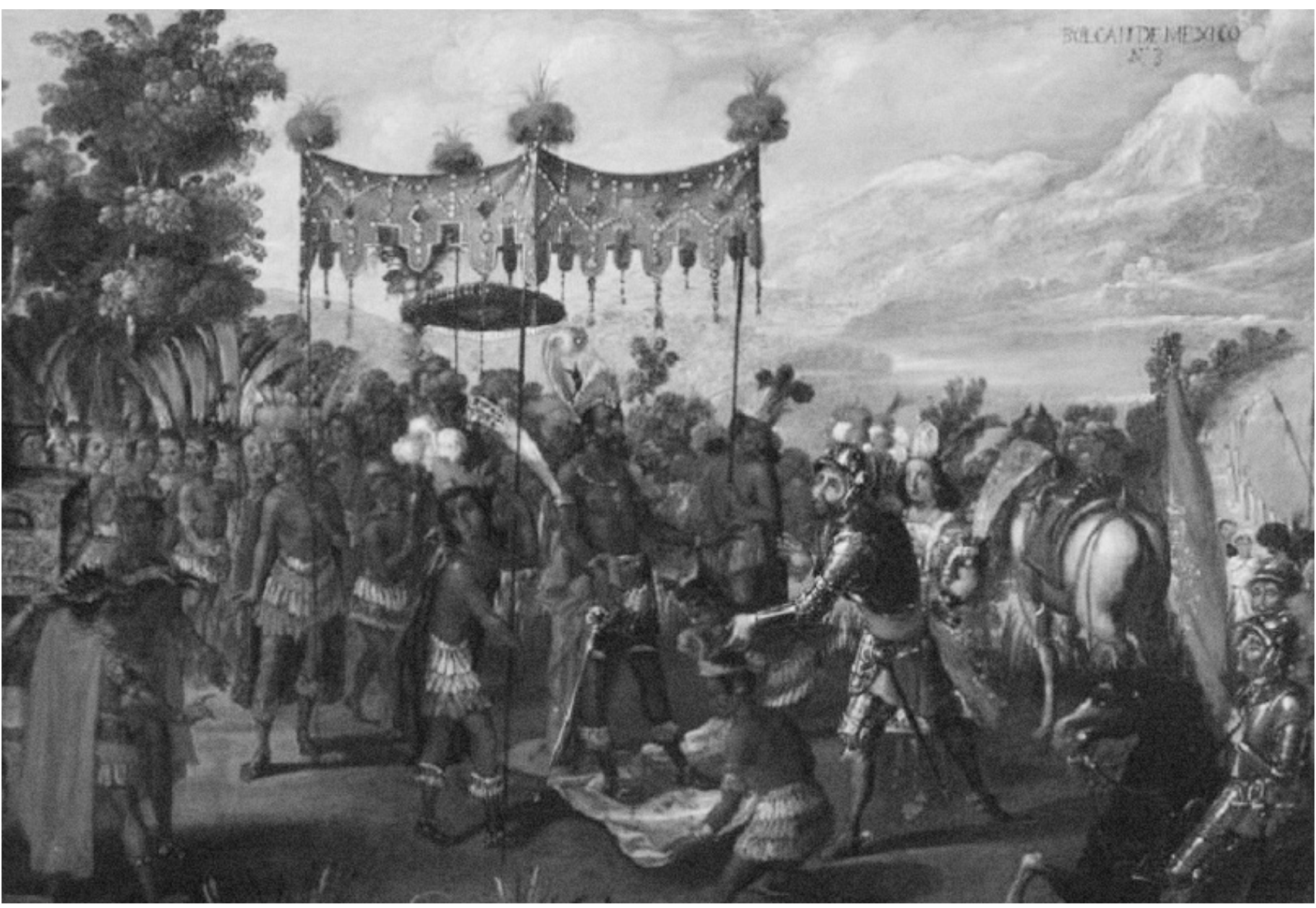

Fuente: Vargaslugo et al. (2005). Imágenes de los naturales en el arte de la Nueva España. Siglos XVI al XVIII. Hernán Cortés y Motecuhzoma son los personajes que protagonizaron maniqueamente durante mucho tiempo el proceso de Conquista.

simpatizaban con Tenochtitlan, pues ciudades como Chalco, Huejotzingo, Texcoco y la afamada Tlaxcala se le oponían y, de hecho, aportaron recursos humanos y numerosos materiales en el asedio final de los lagos del Altiplano (Navarrete Linares, 2019).

Asimismo, debemos entender que las guerras de conquista, en plural, fueron procesos de múltiples vertientes, líneas y derivaciones cuyo desentrañamiento nos puede ayudar a entender el abigarrado mosaico social, los conflictos políticos y las exigencias sociales de justicia por las que pasamos en nuestra actualidad, en la que los Estados Nación latinoamericanos de origen decimonónico atraviesan momentos cruciales en los que los pueblos movilizados en sus regiones y capitales buscan el reconocimiento efectivo de su plurinacionalidad (Casaús Arzú, 2010: 205-245; Sánchez, 2019). Por ello, urge que los estudiosos del pasado comprendamos la centralidad de la discusión en estos momentos sociales críticos, para así colaborar en la construcción de un sistema jurídico-político que haga valer la autodeterminación de los pueblos, el respeto al libre ejercicio de sus culturas y a sus devenires epistémicos (Martínez Luna, 2015: 99-112; Tzul Tzul, 2019). ${ }^{3}$

3 La discusión nutrida desde la ciencia política crítica reflexiva escapa del terreno de estudio de la episteme humana y la construcción del pasado, la cual, sin embargo, es referente necesario para la construcción 
Como se ha señalado en otros trabajos, las fuentes no deben ser leídas linealmente, ni su contenido ha de tomarse al pie de la letra; es necesario asomarse entre sus líneas, rebuscar cuidadosamente entre sus pliegues para identificar las visiones del mundo y las voces lejanas que nos llegan desde los siglos XVI o XVII: las relaciones, las crónicas y las historias generales guardan un sinnúmero de elementos entretejidos de otras fuentes más tempranas que fueron destruidas o interpretadas por frailes franciscanos (con todas las limitantes culturales y riesgos anacrónicos que posee tal verbo con la dura visión escatológica de los padres seráficos) (Weckmann, 1982), y posteriormente revisitadas por un sinnúmero de especialistas lectores (intérpretes y censores) en los que se ancló la tarea de construir el aparato de gobierno castellano en el virreinato de la Nueva España (Friede, 1959).

La reflexión sobre las representaciones históricas de los protagonistas de la Conquista regularmente permite avizorar que tales retratos tienen por marco una concepción occidental del proceso bélico, algo que plantea grandes retos a los historiadores cuando se enfrentan al análisis de las diferentes narrativas sobre dicho suceso.

Y éste no es el único problema: también hay que sacar en claro las circunstancias y contextos, muchas veces oscuros y multiformes, en medio de las cuales se buscó construir un nuevo régimen político en el territorio del Altiplano Central mesoamericano, en donde se ubicaba la hegemonía nahua mexica-tenochca.

Es menester espigar en los testimonios de los hechos de armas y sondear en las intenciones de quienes registraron aquellas acciones que marcarían la desaparición de los antiguos centros gobernantes prehispánicos y el surgimiento de un complejo territorial y político conflictivo y de estructuras sociales discordantes en lo social, lo cultural, lo político y lo religioso que se llamaría,

de lo que Robert Dahl denominó Poliarquía. De ahí que consideremos urgente que los investigadores de la disciplina histórica se involucren en la discusión de otras formas de enunciar y participar de lo político (Dahl, 2009). uniformemente, Nueva España (Botta, 2017: 49-79; Durán, 2016: 115-143). ${ }^{4}$

Algunos problemas sobre las narrativas de la conquista de Tenochtitlan se deben a que no todos los relatos son historias, es decir, narraciones que deliberadamente recuerdan y preservan hechos pasados. En realidad, las primeras referencias a la conquista están en las Cartas de Relación (Cortés, 2010) que el propio Hernán Cortés escribió al emperador Carlos V, entre 1520 y 1526, para contarle aquello que estaba ocurriendo en su presente. $Y$ tampoco los escritos de los hombres que acompañaron a Cortés pueden llamarse historias en sentido estricto: la obra de Andrés de Tapia, de 1533 (2008); la de Bernardino Vázquez de Tapia, de 1543 (1939); y la de Francisco de Aguilar, hacia 1560 (1980) fueron relaciones o informes que tenían propósitos específicos, no siempre equiparables a los de un historiador. La naturaleza de este tipo de fuentes puede deberse a que:

[...] la redacción de relaciones y crónicas devino una forma de obtener recompensas o beneficios del favor real. De este modo, tanto particulares como miembros de las corporaciones (por ejemplo, la Iglesia) elaboraron sus historias y trataron de hacerlas llegar al soberano, manuscritas o ya impresas, como medio para destacar sus méritos personales, los de su estamento o los de sus institutos [...] (Battcock y Barjau, 2018, 10).

Sin embargo, sí hubo un par de historias de la conquista que se escribieron varios años después y con el fin de recoger la memoria de lo acontecido desde el momento del desembarco cortesiano, en 1519, hasta el derrumbamiento final del poderío mexica, en 1521. La primera de éstas fue la obra del sacerdote Francisco López de Gómara, quien en 1552 publicó su Historia de las In-

4 La discusión en torno a la comprensión de procesos de conquista, como la evangelización, debe partir desde la propia conceptualización occidental cristiana europea de las categorías implementadas para explicar a los conquistados, como lo es en el caso de lo que la academia ha constituido como "religiones prehispánicas". 
dias y de la conquista de México (1985). Gómara construyó su relato con los informes que obtuvo directamente de Hernán Cortés y de otros conquistadores, y también con textos como las Cartas de Cortés y la relación de Andrés Tapia. La segunda, la Historia verdadera de la conquista de la Nueva España, de Bernal Díaz del Castillo (2019), terminada hacia 1568, tuvo por objetivo desmentir o refutar muchas afirmaciones de la narración histórica de Gómara, aquellas que Bernal consideraba falsas o inexactas.

Con base en los textos arriba mencionados, en los siglos posteriores se elaborarían todas las historias relativas a la conquista de los dominios de México Tenochtitlan. Sin embargo, no puede decirse que con la caída de la gran capital tenochca, en 1521, se consumase el proceso de dominación española.

Fuera de lo que hoy es el territorio central de México, que fue el que adoptó el nombre de la Nueva España, y en territorios muy extensos y distantes, tanto al sur como al norte, había otras tierras ocupadas por otras comunidades y grupos a los que los españoles también trataron de someter, cuyas guerras de conquista durarían mucho más tiempo. Sólo por dar un ejemplo, en el actual estado de Yucatán, un antiguo señor llamado Ah Nakuk Pech, que al ser bautizado adoptó el nombre de Pablo Pech, escribió un compendio de anales intitulados Chac-Xulub-Chen (1936), los cuales cuentan la historia de lo que podríamos calificar como "la conquista de Yucatán": la llegada de los españoles a la región, el principio de la colonización y la cristianización, la rebelión indígena en la península en el año de 1546, entre otros sucesos que transcurren entre los años de 1511 y 1560 .

Claramente, aquello que llamamos historia de la conquista ni concluyó en un año preciso ni su relato se ha construido siempre a partir de historias -valga el pleonasmo- sino con narraciones de diferente tipo e intencionalidad y que, sólo al paso del tiempo, se convertirían en fuentes, pues a través de diversos procesos en diferentes épocas, las culturas fueron modificando, reestructurando y buscando nuevas estrategias de gobierno en torno al cambiante y poco estable sistema político de las regiones, a la par que se reestructuraban las relaciones de dominación étnica bajo complejos esquemas de legitimidad política y procesos de resistencia que distan de haberse discutido hasta sus últimas consecuencias y que tienen varias aristas pendientes hasta nuestros días (León Cázares et al., 1992; Vos, 2015).

Reconsiderar la guerra de conquista y la lucha entre los pueblos amerindios y los colonizadores europeos demanda tomar en cuenta la cosmovisión de los soldados españoles que se embarcaron rumbo a las nuevas tierras. Para ello, es necesario tener en mente sus idearios y anhelos: la búsqueda de ciudades perdidas, la promesa de riquezas y las ansias de los honores y la glorias que les permitieran incorporarse a la aristocracia dominante de las cortes europeas. Muchos de ellos tuvieron la posibilidad de dejar registro escrito de sus andanzas, y no pocos también la necesidad de referirlas a sus superiores a fin de que éstos les reconocieran y retribuyeran sus servicios (Weckmann, 1992). A estos informes inmediatos, comúnmente denominados "relaciones", pertenecen las primeras noticias que Hernán Cortés envió al emperador Carlos $V$ y que no sólo incluyen sus proezas, sino que inician con un sumario de las dos primeras expediciones a las costas continentales del sureste de lo que hoy llamamos Mesoamérica, emprendidas respectivamente por Francisco Hernández de Córdoba y Juan de Grijalva, entre 1517 y 1518.

Con respecto al espacio mesoamericano debemos hacer un pequeño paréntesis explicativo. Dicho modelo de super área cultural se creó en 1943, en una formulación teórica del estudioso alemán Paul Kirchhoff (1992), quien propuso delimitarla a partir de la composición de las familias lingüísticas originarias y de la presencia o ausencia de determinados rasgos culturales: el cultivo de algunos frutos, las técnicas constructivas, las formas de computar el tiempo, entre otros. Aunque el modelo no ha estado exento de críticas (Nalda, 1990), ha resultado útil para los entramados explicativos 
de los especialistas, pues aporta un terreno común de diálogo en el estudio de los fenómenos humanos de estas áreas, desde los tiempos prehispánicos hasta el de las múltiples avanzadas de conquista; es decir que del modelo mesoamericano propuesto hace más de medio siglo al que podría entretejerse en nuestros trabajos contemporáneos hay un largo camino por labrar (Williams, et al., 2011), en el que quizá una de las rutas se fundamente en estudiar a detalle los elementos de diferenciación y de cambio cultural que bajo presión han ocurrido entre los diferentes pueblos que habitan y significan las distintas regiones.

De vuelta al proceso de conquista, diremos que de las seis cartas de relación cortesianas que se conocen, nos interesan particularmente las tres primeras, es decir, aquellas que incluyen noticias desde la fundación del Ayuntamiento de la Vera Cruz, hasta las informaciones enviadas tras el colapso del orden político mexica en la cuenca del Altiplano Central, en las cuales la argumentación constante del paradigma de la guerra justa cristiana desde los ojos del conquistador, y la narrativa descriptiva del territorio y los regímenes de gobierno establecidos son una preocupación central (Bataillon et al., 2008). ${ }^{5}$

Es menester recordar que los soldados, vasallos de la corona de Castilla, tenían experiencia previa en la conquista y colonización de territorios americanos, pues ya habían ocupado las islas del Caribe y domeñado a sus pobladores. Con ese bagaje vivencial y lingüístico vieron y nombraron las nuevas realidades continentales que enfrentaron: los templos ceremoniales fueron denominados cúes y a los señores y líderes principales de las poblaciones se les denominó caciques.

\footnotetext{
5 Debemos recuperar el conocimiento jurídico castellano del siglo XVI para entender la notoriedad con la que se producen regímenes escriturísticos en cuanto a lo legal en el proceso de conquista, en el que además se desborda el sentido cristiano-castellano de "la guerra justa", que en el caso de las relaciones cortesianas es tomado como un espacio semiótico contenido en una narrativa en la que se configura un imaginario glorificador en torno a la profundidad ideológica de "la fe" y el honor trascendental del soldado entregado a ella y a su representación terrena: la monarquía castellana.
}

Aparte de dar nombre a la novedad, que era una forma de apropiación, la cultura hispánica determinaba que el segundo paso era modelarla jurídicamente, con leyes y autoridades que la rigiesen en representación de su monarca. Cortés sabía algo de derecho, conocimiento aprendido en sus años de bachiller en Salamanca, y por ello fundó un cabildo en la costa veracruzana. Esto cumplía un triple propósito: en principio establecía un poder en el territorio recién ocupado, y como consecuencia este mismo cuerpo autorizaba su ruptura con la autoridad castellana radicada en la isla de Cuba y daba su licencia para emprender el avance tierra adentro, provocando conflictos que incluso complicarían la estancia de Cortés en el Altiplano, al tener que volver a la costa a enfrentar a Pánfilo de Narváez, quien traía órdenes de apresarlo y llevarlo de vuelta a Cuba.

Al fundar el ayuntamiento, Cortés no podía aguardar: deseaba enterarse de la situación política de los pueblos que iba encontrando, quería persuadirlos de hacerse sus aliados y, sobre todo, anhelaba contemplar con sus propios ojos el centro rector al que parecían responder todos los caciques: Tenochtitlan.

Las relaciones de Cortés pintan con elocuencia los escenarios y a los actores, reproducen vívidamente las batallas justas, hablan del asombro y las miserias de sus huestes; todo desde el punto de vista del capitán que busca realzar sus hazañas, un sujeto que transita en pos del reconocimiento de su prestigio y de la honra que a él va aparejada. Así traduce las grandezas de unos territorios nuevos que "van reconociendo y rindiendo vasallaje" a la autoridad real de la península ibérica. ${ }^{6}$

Cortés esperaba de su emperador el justo premio a su inédito servicio, pues someter

6 El trasfondo interpretativo de los hechos históricos narrados por Cortés y la representación de su figura en un modelo biográfico trasciende los trazos argumentativos que nos hemos planteado para este texto. Sin embargo, no es un asunto menor entrever la dificultad hermenéutica que conlleva proponer un ejercicio crítico de las relaciones como exponentes históricos de la vida de un sujeto en el contexto hispánico del siglo XVI (Nava Sánchez, 2018: 9-40). 
un mundo nuevo con el solo valor de su brazo ameritaba una muy generosa retribución: ser elevado a una dignidad señorial. El Conquistador tenía, como cabría esperar, una visión genuinamente europea, híbrida de letrado y de hombre de capa y espada, que buscaba herramientas dentro de su propio acervo cultural para sujetar y dominar lo desconocido y para explicar lo culturalmente intraducible.

Por otro lado, don Hernando advierte en sus escritos de manera sutil, pero insistente, que no todos los grupos que ha encontrado hablaban un mismo idioma; no obstante, logra entenderse con ellos. Por las solas cartas uno alabaría su enorme habilidad y su gama de recursos, de no ser porque sabemos que en el discurso hay una omisión: la de Malintzin o Marina, la mujer que le fue entregada como parte de una ofrenda. Ella y Jerónimo de Aguilar fueron sus intérpretes en cadena: Malintzin traducía del náhuatl al maya y Aguilar vertía lo dicho en esta lengua al castellano, a fin de que lo entendiera el capitán (Townsend, 2015).

En cambio, las Cartas de Relación (figura 2) sí se vuelven explícitas cuando se trata de referir los pactos y alianzas de Cortés con grupos enemigos de los mexicas que, sumados a su puñado de hombres de armas, formaron la gran hueste que encaró el poder de la Excan Tlatoloyan de la Cuenca de México, la famosa triple alianza -política, económica y militar- liderada por los tenochcas (Battcock, 2019).

Pasajes también de gran viveza y energía son los que se dedican a la entrada de la tropa española a Tenochtitlan, al encuentro con Motecuhzoma Xocoyotzin en la calzada meridional de la ciudad y al periodo de residencia en el recinto urbano, en el que el propio Motecuhzoma, ante la formulación del requerimiento conquistador, entrega el reino y su corona a la sacra cesárea católica majestad de Carlos V. La última parte del drama nos conduce por el inicio del sitio, el acoso y arrinconamiento de los mexicas en Tlatelolco, antes del episodio final en la que el último Tlahtoani, Cuauhtemotzin, es apresado y conducido ante las tropas castellanas.

\section{Figura 2 \\ Inicio de una de las relaciones de Hernán Cortés, dirigida a Carlos V}

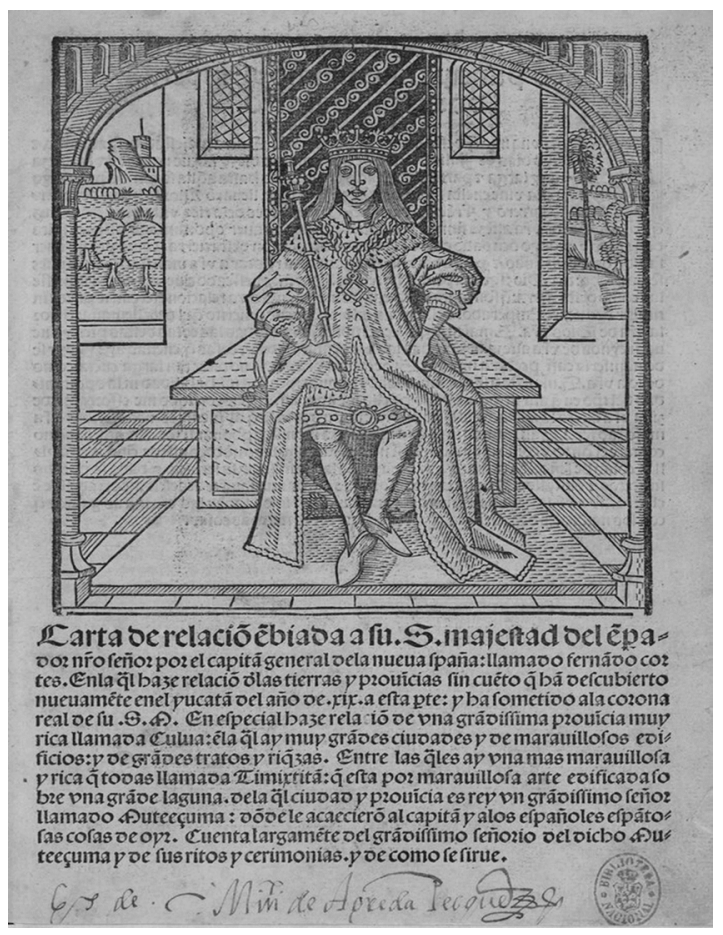

Fuente: Hernán Cortés (1522). Imagen procedente de los fondos de la Biblioteca Nacional de España.

De sobra es sabido que no fue exclusivamente Cortés quien dejó testimonio de las guerras de conquista, aunque la historia decimonónica haya tratado de cotejar los hechos para validarlos como reales.

Aquí radica el punto de quiebre con una historiografía que desmonte y busque complejizar los grandes mitos nacionales elaborados por la erudición criolla: debemos arrojar una mirada hermenéutica que indague las posibilidades y las razones que versan sobre el relato de la Conquista, y para ello tenemos acceso a un sinfín de obras para revisar y para encontrar los ejes que las estructuran.

Quizá la Historia Verdadera de la Conquista de la Nueva España, de Bernal Díaz del Castillo (figura 3), sea el texto más socorrido debido a que trata de un soldado que reclamó décadas después, para sí y sus compañeros de armas, sus partes de la gloria bélica que Cortés quiso monopolizar. 
El de Bernal es un recuento tan épico como el cortesiano, pero sin duda menos grandilocuente, mucho más apegado a lo terrenal y a lo colectivo: él no acalla los méritos de Malintzin y de Aguilar, sin cuyas voces jamás habrían entendido los españoles el balance de poder en los territorios sobre los que avanzaban.

Sobre todo, en su narrativa destaca la presencia de la mujer, no sólo por su destreza de traductora, sino por su habilidad para abrir espacios y fomentar contactos, lo que hace de ella una pieza fundamental al lado de Cortés en el diseño de tácticas de conquista.

\section{Figura 3 \\ Bernal Díaz del Castillo, autor de la Verdadera Historia de la Conquista de la Nueva España}

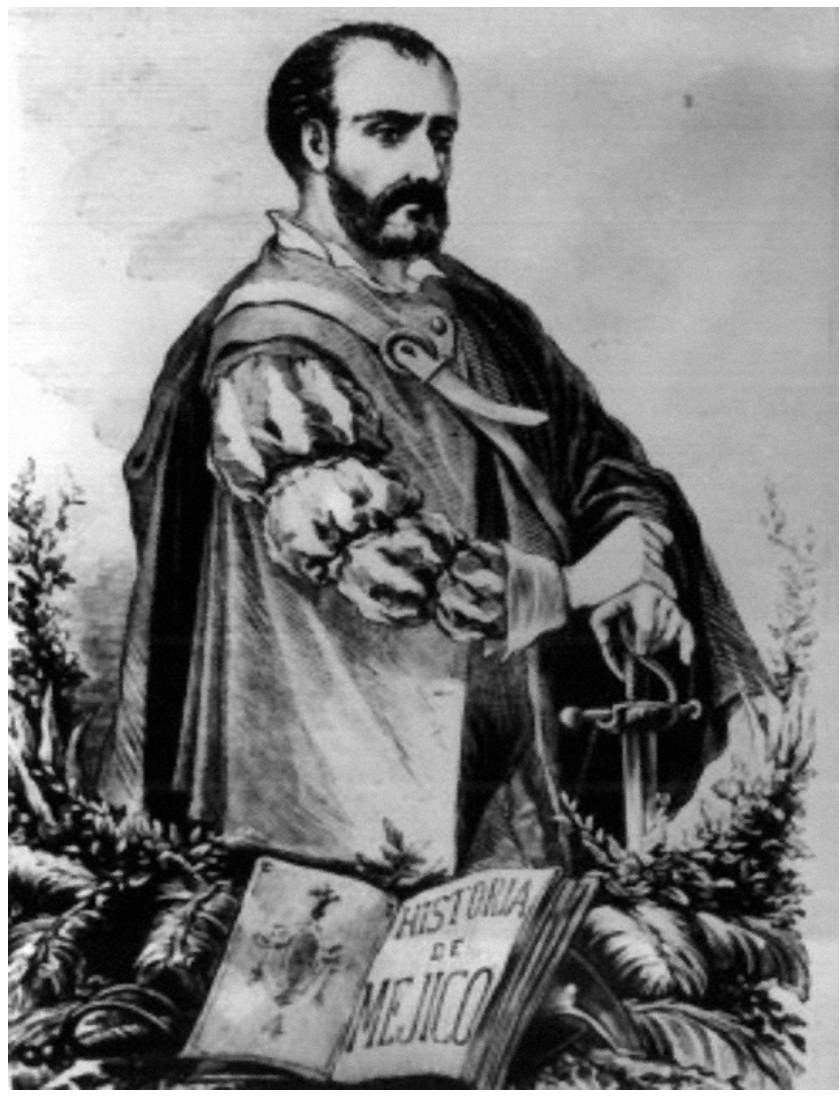

Fuente: Mediateca INAH (2020).

\section{Conclusiones}

En suma, la información plasmada en el corpus documental sobre la Conquista del Altiplano Central Mesoamericano no es homogénea en sus contenidos, pues las composiciones y sus códigos escriturarios, e incluso pictóricos (como el Lienzo de Tlaxcala, por citar un ejemplo) no permiten homologarlos. Los registros deben leerse como complejos interpretativos con intenciones específicas de las que sus autores podían beneficiarse para recomponer sus posiciones políticas, sociales y económicas en un orden convulso, del cual se desprende que una nueva labor historiográfica intente dar respuestas a las inquietudes que despiertan estos hechos, en la coyuntura de los 500 años. Seguramente, estas labores nunca tendrán un cierre de elaboración definitiva y seguirán atrayendo numerosos acercamientos críticos que busquen dar sentido a las preocupaciones sociales contemporáneas por explicar el pasado; sin embargo, es una tarea urgente revisar las nuevas posiciones sociales que se involucren en el tejido de otras miradas historiográficas que procuren hilar posiciones que detonen otras historicidades posibles, en un momento en el que nuestras sociedades latinoamericanas deben reconocerse plurales, multiculturales y con historicidades diversas.

Las narrativas del proceso de sometimiento de los pueblos es la imagen dolorosa de una herencia cultural, social, política, religiosa, lingüística y simbólica que la Conquista castellana, en sus idearios más ortodoxos, amenazaba extinguir.

Sin embargo, la herencia persistió, en gran parte tramada en un conjunto notable de textos donde se entreveran diversas tradiciones discursivas, múltiples y heterogéneos actores, diferentes voces y complejos lugares de enunciación. Crónicas, testimonios, cartas, documentos legales y religiosos entre otros, que produjeron los conquistadores, los soldados, los evangelizadores, los nobles indígenas y los difusos y polémicos sujetos mestizos son evidencia de dicho fenómeno sociocultural. 
Serge Gruzinski formuló una pregunta clave en el inicio de su formidable libro $L a$ colonización de lo imaginario: "¿cómo construyen y viven los individuos y los grupos su relación con la realidad, en una sociedad sacudida por una dominación exterior sin antecedente alguno?" (1991: 9), interrogante indispensable en el marco más amplio del México conquistado y dominado por los españoles entre los siglos XVI y XVIII. Su propuesta se dirige a revisar el rico archivo de testimonios conservado, sin dejar de advertir que dicha textualidad, atravesada por "cierta pasión de la escritura", fue elaborada y redactada en el contexto trastocado de la conquista y posterior colonización. Interrogar este acervo implica revisar conceptos tales como memoria, identidades, alteridades. Esta pasión de escritura atravesó tanto a los sujetos conquistadores como a los sujetos indígenas y mestizos que rápidamente adoptaron su uso como estrategia para, como señala Martín Lienhard, negociar y conservar una autonomía relativa (1992: XII).

Sin duda, la conquista de México en tanto acontecimiento histórico es una trama textual compleja que, como destaca Lienhard, implica la combinación de variados medios y códigos semióticos. Proponemos que el diálogo entre el discurso histórico y el discurso literario resulta revelador en cuanto privilegia el descentramiento de la mirada unívoca y la potencia de la lectura entre líneas, que además ocupa una preocupación central en la trascendencia de la acción y su inmanencia en la memoria.

Bajo ese supuesto, debemos acotar nuestras atenciones a las intencionalidades escriturísticas que tras de sí convergen en una red de valores y de estrategias relacionales del autor con el mundo, las cuales son extensivas a los entramados de la memoria, pues es sólo a través de ellos que los conquistadores se atrevieron a difundir la narrativa de su propia figura, enaltecer sus decisiones y glorificar sus combates, debido a que sus manuscritos fueron vehículo para hacerse valer como señores principales de honor y de fe en los nuevos territorios conquistados, bajo su pluma, por ellos mismos.
Estas aprehensiones de la narrativa conquistadora han sido reivindicadas en infinidad de ocasiones para sostener aparatos de legitimidad y distinción entre las múltiples sociedades que han habitado estos territorios. Primero entre castellanos y peninsulares, cuyo alarde institucional era ritualizado cada 13 de agosto, día de San Hipólito, en el paseo del pendón. Luego entre la invención del criollo y el mestizo, que vetó el presunto honor del conquistador castellano, pero que a la par se despojó de identificarse entre los vencidos: quienes habían muerto y habían sido profusamente olvidados. $Y$ es detrás de ese sello de la muerte lo que encierra ese último giro narrativo que debemos traer a nuestra argumentación sobre el registro y la memoria en la crónica de conquista: el olvido como ese espectro que diluye la presencia de lo moralmente reconocible, que ante la inminencia de la muerte insta a los honorables vivos a dejar sendos retratos manuscritos de las acciones en vida, y con ello ser moralmente dignos de auto-reconocerse a sí mismos como memorias, claro está que no uniformes, sino contradictorias, potencialmente especulativas, y de constante impresión de sus hazañas y sus fobias ante la finitud de lo real (Aries, 2011).

Las memorias, en este caso registradas por las crónicas de conquista, son el principal punto de inflexión de lo que Ricoeur considera como una aporía: la complejidad incalculable de los tiempos experienciales narrados, frente al tiempo concretado en lo ocurrido (2004). He aquí el énfasis en que las crisis de los modelos explicativos de la historia instiguen contra los baluartes supuestamente incorruptos de la tradición y reflexionen críticamente sobre lo legítimo, para que con ello se proponga la formación de otras tendencias de reflexión sobre los procesos conciénciales de lo humano, las cuales examinen los linderos epistémicos que se cultivaron en las miradas narrativas de los conquistadores. Será a través de procesos revisionistas de nuestros pasados mediante los cuales nos encontremos con las tenues siluetas imaginarias de los aliados, enemigos, complicidades y justificaciones 
del conquistador. Es decir, reflexionar la conquista no sólo procede de nuestra necesidad de fundamentar el pasado, sino que también parte del siempre útil atino de discutir los modelos de cambio y percepción de nuestros conflictos como humanos en sociedad. Discusiones que no son, ni de cerca, un compendio de lecciones al que nos atrevamos intempestivamente a tildar como superadas.

\section{Fuentes consultadas}

Aguilar, Francisco de (1980), Relación breve de la conquista de la Nueva España, México, Universidad Nacional Autónoma de México-Instituto de Investigaciones Históricas.

Aries, Philippe (2011), El hombre ante la muerte, Madrid, Editorial Taurus.

Asselberg, Florine G.L. (2007), "The Conquest in Images: Stories of Tlaxcalteca and Quauhquecholteca Conquistadors", en Laura E. Matthew y Michel R. Oudijk (eds.), Indian Conquistadors. Indegenous allies in the Conquest of Mesoamérica, Norman, University of Oklahoma Press, pp. 65-101.

Bataillon, Gilles; Bienvenu, G. y Velasco Gómez, Ambrosio (2008), Las teorías de la Guerra Justa en el siglo XVI y sus expresiones contemporáneas, México, Universidad Nacional Autónoma de México-Facultad de Filosofía y Letras.

Battcock, Clementina (2019), "Introducción. Mover enfoques, otras perspectivas de lectura de los antiguos textos novohispanos", Dimensión Antropológica, 76 (26), México, Instituto Nacional de Antropología e Historia, pp. 7-11.

Battcock, Clementina y Barjau, Luis (2018), "Las crónicas novohispanas: un caleidoscopio", en Lo múltiple y lo singular. Diversidad de perspectivas en las crónicas de la Nueva España, México, Instituto Nacional de Antropología e Historia.
Botta, Sergio (2017), "Representar a los dioses indígenas a través de San Agustín. Huellas del De civitate Dei en las obras de fray Bernardino de Sahagún y fray Juan de Torquemada", Mudables representaciones: el indio en la Nueva España a través de crónicas, impresos y manuscritos, México, INAH, pp. 49-79.

Casaús Arzú, Marta Elena (2010), "Repensar la nación y la reforma del Estado por las élites mayas: del Estado homogéneo al Estado plural en Guatemala", en Reformas del Estado, movimientos sociales y mundo rural en el siglo XX en América Latina, coord. Antonio Escobar Ohmstede, Fernando I. Salmeron, Laura Valladares de la Cruz y Ma. Guadalupe Escamilla Hurtado, México, Universidad Nacional Autónoma de México, Instituto Nacional de Antropología e Historia, Centro de Investigaciones y Estudios Superiores en Antropología Social, Universidad Iberoamericana, Universidad Autónoma Metropolitana, Colegio de Etnólogos y Antropólogos Sociales, pp. 205-245.

Cortés, Hernán (2010), Cartas de Relación y otros textos, Edición, prólogo y notas de Valeria Añón, Buenos Aires, Corregidor.

Cortés, Hernán (1522), Cartas de Relación, Sevilla, Imprenta de Jacobo Cromberger, <https://bit.ly/3aSoK7Z>, 5 de febrero de 2020.

Dahl, Robert A. (2009), La poliarquía. Participación y oposición, Madrid, Tecnos.

Díaz del Castillo, Bernal (2019), Historia verdadera de la Conquista de la Nueva España, México, Editorial Porrúa.

Díez-Canedo, Aurora (2019), "Francisco Cervantes de Salazar desglosado. El humanismo español del siglo XVI, la sociedad novohispana y la crónica de la conquista”, en Luis Barjau y Clementina Battcock (coords.), Lo múltiple y los singular. Diversidad de perspectivas en las crónicas de la Nueva España, Instituto Nacional de Antropología e Historia, pp. 103-132. 
Duve, Thomas (2007), "El privilegio en el antiguo régimen y en las Indias. Algunas anotaciones sobre su marco teórico legal y la práctica jurídica", en Beatriz Rojas (coord.), Cuerpo político y pluralidad de derechos. Los privilegios en las corporaciones novohispanas, México, CIDE/Instituto Mora, 2007.

Durán, Norma (2016), "La evangelización de Mesoamérica en el siglo XVI: una aproximación crítica", en Historia y Grafía, núm. 47, 2016, México, Universidad Iberoamericana, pp. 115-143.

Feierstein, Daniel (2012), Memorias y representaciones sobre la elaboración del genocidio, Buenos Aires, Fondo de Cultura Económica.

Friede, Juan (1959) "La censura española del siglo XVI y los libros de Historia de América", en Revista de Historia de América, núm. 47, Colima, Instituto Panamericano de Historia y Geografía, pp. 45-94.

Gruzinski, S. (1991), La colonización de 10 imaginario. Sociedades indígenas y occidentalización en el México español. Siglos XVI-XVIII, México, Fondo de Cultura Económica.

Herrera, Robinson (2007), "Concubines and Wives: Reinterpreting Native.Spanish Intimate Unions in Seixteenth-Century Guatema", en Laura E. Matthew y Michel R. Oudijk (eds.), Indian Conquistadors. Indegenous allies in the Conquest of Mesoamérica, Norman, University of Oklahoma Press, pp. 127-144.

Instituto Nacional de Antropología e Historia (2020), "Bernal Díaz del Castillo. Dibujo", Colección Archivo Casasola, Fototeca Nacional (1920), Ciudad de México, <https://bit.ly/3p91Pdl>, consultado el 5 de febrero de 2020.

Joutard, Philippe (1986), Esas voces que nos llegan del pasado, México, Fondo de Cultura Económica.

Kirchhoff, Paul (1992), "Mesoamérica. Sus límites geográficos, composición étnica y características culturales", en Jorge A. Vivó (ed.), Una definición de Mesoamérica, México, UNAM,-Instituto de Investigaciones Antropológicas, pp 2845.

León Cázares, María del Carmen; Ruz, M. Humberto y Alejos García, J. (1992), Del Katún al siglo. Tiempos de colonialismo y resistencia entre los mayas, México, Consejo Nacional para la Cultura y las Artes.

León-Portilla, Miguel (1964), El reverso de la conquista. Relaciones aztecas, mayas e incas, México, Mortiz.

Lienhard, M. (1992), Testimonios, cartas y manifiestos indígenas (Desde la conquista hasta comienzos del siglo $X X$ ), Caracas, Biblioteca Ayacucho.

Lienhard, M. (2008), Disidentes, rebeldes, insurgentes. Resistencia indígena y negra en América Latina. Ensayos de historia testimonial, Madrid, Iberoamericana/ Vervuert, 2008

López de Gómara, Francisco (1985), Historia General de las Indias, Barcelona, Biblioteca de Historia.

Martínez Luna, Jaime (2015), "Conocimiento y comunalidad", Bajo el volcán, 23 (15), Puebla, Benemérita Universidad Autónoma de Puebla, pp. 99-112

Martínez Martínez, María del Carmen (2013), Veracruz 1519. Los hombres de Cortés, México, Instituto Nacional de Antropología e Historia/Universidad de León.

Matthew, Laura E. (2007), "Whose Conquest? Nahua, Zapoteca, and Mixteca Allies in the Conquest of Central America", en Laura E. Matthew y Michel R. Oudijk (eds.), Indian Conquistadors. Indegenous allies in the Conquest of Mesoamérica, Norman, University of Oklahoma Press, pp. 102-126.

Nalda, Enrique (1990), “¿Qué es lo que define Mesoamérica? La validez teórica del concepto Mesoamérica", en XIX Mesa Redonda de la Sociedad Mexicana de Antro- 
pología, México, Instituto Nacional de Antropología e Historia, Colección Científica.

Nava Sánchez, Alfredo (2018), "Los límites de la biografía en Nueva España. Tres biografías de Hernán Cortés y una Relación de Méritos y Servicios como biografema", en Tzintzun. Revista de estudios históricos, núm. 67, Zamora, Michoacán, El Colegio de Michoacán, pp. 9-40.

Navarrete Linares, Federico (2019), Quién conquistó México, México, Debate.

O'Gorman, Edmundo (2007), "La conciencia histórica de la Edad Media", en Historiología. Teoría y práctica, México, México, Universidad Nacional Autónoma de México, pp. 29-66.

Oudijk, Michel R. y Restall, Matthew (2007), "Mesoamerican Conquistadors in the Sixteenth Century", en Laura E. Matthew y Michel R. Oudijk (eds.), Indian Conquistadors. Indegenous allies in the Conquest of Mesoamérica, Norman, University of Oklahoma Press.

Pastrana, Miguel, (2004), Historias de la Conquista. Aspectos de la historiografía de tradición indigena, México, Universidad Nacional Autónoma de México-Instituto de Investigaciones Históricas.

Pech, Nakuk (1936), Historia y crónica de Chac-Xulub-Chen, México, Talleres Gráficos de la Nación.

Ricoeur, Paul (2004), Tiempo y narración, tomo II, México, Siglo XXI.

Romero Galván, José Rubén (2003), "Introducción”, en José Rubén Romero Galván (coord.), Historiografía novohispana de tradición indigena, v. I, México, Universidad Nacional Autónoma de México-Instituto de Investigaciones Históricas, pp. 11-20.

Rozat, Guy (2001), Los origenes de la nación. Pasado indígena e historia nacional, México, Universidad Iberoamericana.
Sánchez, Consuelo (2019), Construir comunidad. El Estado plurinacional en América Latina, México, Siglo XXI.

Tapia, Andrés de (2008), Relación de la conquista de México, México, Axial, Colofón.

Townsend, Camila (2015), Malintzin. Una mujer indígena en la Conquista de México. México, Ediciones Era.

Turner, Guillermo (2016), La biblioteca del soldado Bernal Díaz del Castillo, México, El Tucán de Virginia, Instituto $\mathrm{Na}$ cional de Antropología e Historia.

Tzul Tzul, Gladys (2019), "La forma comunal de la resistencia", Revista de la Universidad de México, núm. 847, abril. México, Universidad Nacional Autónoma de México, <https://bit.ly/3oWdiNu>, consultado el 5 de febrero de 2021.

Vargaslugo, Elisa; Ángeles Jiménez, Pedro; Escalante Gonzalbo, Pablo; Fernández Quintero, Norma; Lorenzo Macías, José María; Martínez del Río de Redo, Marita; Morera, Jaime y Rodríguez-Miaja, Fernando E. (2005), Imágenes de los naturales en el arte de la Nueva España. Siglos XVI al XVIII, México, Fomento Cultural Banamex, A.C.

Vázquez de Tapia, Bernardino (1939), Relación del conquistador Bernardino Vázquez de Tapia, México, Editorial Polis.

Vos, Jan de (2015), La paz de Dios y la paz del Rey. La conquista de la Selva Lacandona (1525-1821), México, Fondo de Cultura Económica.

Weckmann, Luis (1992), La herencia medieval de México, México, Fondo de Cultura Económica.

Weckmann, Luis (1982), "Las esperanzas milenaristas de los franciscanos de la Nueva España", en Historia Mexicana, vol. 32, no. 1 (125), julio-septiembre, México, El Colegio de México, 1982.

Williams, Eduardo; García Sánchez, Magdalena; Weigand, Phil C. y Gándara, Manuel (2011), Mesoamérica. Debates y perspectivas, México, El Colegio de Michoacán. 
Recibido: 15 de diciembre de 2020. Reenviado: 28 de diciembre de 2020. Aceptado: 28 de enero de 2021.

\section{Clementina Battcock}

Doctora en Historia por la UNAM. Profesora investigadora de la DEH- INAH, centro en el que dirige el proyecto "Crónicas novohispanas y andinas". Miembro del Sistema Nacional de Investigadores, nivel I. Es co-coordinadora de diferentes redes de investigación internacional entre las que destaca el Proyecto Crónica Mexicana. Su más reciente libro publicado se titula Manuscritos mexicanos perdidos y recuperados (México, INAH, 2019), así como el artículo en coautoría con José Rubén Romero Galván: "Chimalpain Cuautlehuanitzin. La transformación del mundo indígena en la construcción de las memorias novohispanas", en L'immagine delle religione indigene nelle cronache novoispane. Nuove vie di indagine, Revista Studi e Materiali di Storia delle Religioni, 86/2 (2020), Dipartamento di Storia, Antropología, Religiones, Arte, Spettacolo, Universidad de la Sapienza, Roma, pp. 592-607 (2020). Recientemente también se publicó su capítulo "El códice de San Mateo Huichapan: su registro del pasado", en el libro Entramados en el Mezquital. Treinta años de investigaciones interdisciplinarias del Proyecto Valle del Mezquital, México, Secretaría de Cultura/Instituto de Antropología e Historia, pp. 341-355.

\section{Jhonnatan Alejandro Zavala López}

Licenciado en Etnohistoria por la ENAHINAH. Actualmente realiza sus estudios de maestría en Historia en la Universidad de Guadalajara. Ha realizado estancias de investigación en el Laboratorio de Historia Oral y en el Posgrado en Sociedad y Patrimonio de la Universidad de Guanajuato, además de colaborar en diferentes proyectos de investigación y docencia en disciplinas históricas y antropológicas. Su último artículo aceptado para publicación en coautoría con Clementina Battcock se titula “Eulogio González, el 'conspirador' de 1928: una alegoría de la representación social de 'lo indígena' en México”, en Contribuciones desde Coatepec (en prensa) Toluca, Universidad Autónoma del Estado de México-Facultad de Humanidades. 